\title{
HUBUNGAN PENGETAHUAN DAN SIKAP PETANI PADI DENGAN PENGGUNAAN APD DI DESA PAKKA'BA KECAMATAN GALESONG UTARA KABUPATEN TAKALAR
}

\author{
Arya Pebruansyah ${ }^{1}$ Abdur Rivai ${ }^{2}$ \\ 12Jurusan Kesehatan Lingkungan Poltekkes Kemenkes Makassar \\ Aryapebruansyah02@gmail.com
}

\begin{abstract}
Agriculture is one of the most important fields in meeting the needs of the community. Most of the products from agriculture are used as the staple food for the people in Indonesia, so large-scale use of pesticides can cause health problems. To minimize these health problems with one effort, namely the use of complete PPE. The purpose of this study was to find out how the relationship between knowledge and attitudes of farmers with the use of PPE in Pakka'ba Village, North Galesong District, Takalar District. The type of research used was observational analytic with the Cross-Sectional approach, namely the dependent variable and independent variables measured simultaneously. The population in this study were all rice farmers in Pakka'ba Village, North Galesong District, Takalar District, which were 300 farmers, with a sample of 171 farmers. Determination of the number of samples in this study was determined by the Slovin formula and data collection was carried out using the simple random sampling method. Data processing is done using Chi-Square test with SPSS, Microsoft Excel, The results showed that the Chi-Square test Continuity Correction obtained was $p$-value 0.00 ( $p$ value> 0.05 ) on knowledge and $p$-value 0.00 ( $p$ value> 0.05 ) on attitudes, and said to influence farmers in Pakka'ba Village, North Galesong District, Takalar District. Based on the results of the study it can be concluded that there is a relationship between knowledge and attitudes of the use of personal protective equipment on rice farmers in Pakka'ba Village, North Galesong District, Takalar District. The understanding and awareness of farmers about PPE need to be improved through counseling, simulation, and training.
\end{abstract}

Keywords: Rice Farmers, Personal Protective Equipment, Knowledge, and Attitudes

\section{ABSTRAK}

Pertanian merupakan salah satu bidang terpenting dalam pemenuhan kebutuhan untuk masyarakat. Hasil dari pertanian tersebut sebagian besar digunakan sebagai bahan pangan pokok masyarakat di indonesia, sehingga penggunaan pestisida secara besar-besaran dapat menimbulkan gangguan kesehatan. Untuk meminimalisir gangguan kesehatan tersebut dengan satu upaya yaitu penggunaan APD yang lengkap. Tujuan dari penelitian ini adalah untuk mengetahui bagaimana hubungan pengetahuan dan sikap petani dengan penggunaan APD di Desa Pakka'ba Kecamatan Galesong Utara Kabupaten Takalar. Jenis penelitian yang digunakan adalah observasional analitik dengan pendekatan Cross Sectional, yaitu variabel dependen dan variabel independen diukur secara bersamaan. Populasi dalam penelitian ini adalah seluruh petani padi yang ada Di Desa Pakka'ba Kecamatan Galesong Utara Kabupaten Takalar yaitu 300 petani, dengan sampel 171 petani. Penentuan jumlah sampel dalam penelitian ini ditentukan dengan rumus Slovin dan pengambilan data dilakukan menggunakan metode simple random sampling. Pengolahan data dilakukan dengan menggunakan uji Chi Square dengan SPSS, Microsoft excel,Hasil penelitian menunjukkan bahwa dengan uji Chi Square dari analisis Continuity Corection yang diperoleh adalah $p$ value 0,00 ( $p$ value $>0,05$ ) pada pengetahuan dan $p$ value 0,00 ( $p$ value $>0,05$ ) pada sikap, dan dikatakan ada pengaruh terhadap petani di Desa Pakka'ba Kecamatan Galesong Utara Kabupaten Takalar. Berdasarkan hasil penelitian maka dapat disimpulkan bahwa ada hubungan antara pengetahuan dan sikap penggunaan alat pelindung diri pada petani padi di Desa Pakka'ba Kecamatan Galesong Utara Kabupaen Takalar. Pemahaman dan kesadaran petani tentang APD perlu ditingkatkan melalui peyuluhan,simulasi, dan pelatihan.

Kata kunci : Petani Padi, Alat Pelindung Diri, Pengetahuan dan Sikap 
Jurnal Sulolipu : Media Komunikasi Sivitas Akademika dan Masyarakat

Vol. 20 No.12020

e-issn : 2622-6960, p-issn : 0854-624X

\section{PENDAHULUAN}

Negara Indonesia adalah Negara Agraris yang sebagian besar penduduknya bermata pencaharian di bidang pertanian. Jumlah petani mencapai $40 \%$ dari jumlah total tenaga kerja di Indonesia atau sekitar 46,7 juta jiwa. Sebagai Negara agraris, mayoritas penduduk Indonesia telah memanfaatkan sumber daya alam untuk menunjang kebutuhan hidupnya dan salah satunya ialah menggantungkan hidup pada sektor pertanian.Dalam hal tersebut sekotr pertanian memiliki peran yang sangat penting karena sebagai penghasil pangan yang cukup besar bagi penduduk yang jumlahnya terus meningkat setiap tahun. Dengan meningkatnya jumlah penduduk setiap tahunnya, masyarakat mulai berpikir untuk meningkatkan hasil produksinya dalam sector pertanian, salah satu cara mereka adalah menggunakan pestisida untuk menurunkan faktor - faktor pengganggu produksi mereka seperti hama (Usman Rifai, 2017). Pertanian merupakan salah satu bidang terpenting dalam pemenuhan kebutuhan untuk masyarakat. Hasil dari pertanian tersebut sebagian besar digunakan sebagai bahan pangan pokok masyarakat di indonesia , misalnya beras,singkong, dan jagung. Hasil lain dari pertanian digunakan sebagai pelengkap bahan pangan pokok.

Salah satu hasil pertanian yag sangat banyak dibutuhkan oleh masyarakat adalah padi. Padi merupakan hasil pertanian yang digunakan oleh sebagian besar pangan pokok, Selain bermanfaat pada bidang pertanian juga ada berbagai masalah, diantaranya gangguan dari hama, masalah cuaca yang dibutuhkan pada saat penanaman maupun panen. Namun, masalah yang sangat berpotensi dalam hal keberhasilan panen adalah gangguan dari hama,Penggunaan pestisida merupakan salah satu upaya yang dilakukan para petani untuk mengatasi masalah tersebut.(Yeviana Dwi Rahmawati,2014).

World Health Organization (WHO) dampak negatif yang di timbulkan pestisida bagi kesehatan masyarakat ataupun petani sangat beracun dan berbahaya.Kontak langsung dengan pestisida ini berisiko keracunan akut maupun kronis.Sakit kepal, mual, muntah dan sebagainya bahkan iritasi pada kulit dan kebutaan merupakan gejala keracunan akut dari pestisida. Data dari Organisasi Kesehatan Dunia (WHO), 1-5 juta kasus keracunan pestisida terjadi pada pekerja di sektor pertanian dimana sebagian besar kasus tersebut terjadi di Negara berkembang yang 20.000 jiwa diantaranya berakibat fatal akibat penggunaan pestisida. (Frity,2017).

Pestisida merupakan bahan kimia yang digunakan untuk memberantas hama sehingga dapat meningkatkan hasil tanam petani. Penggunaan pestisida oleh petani semakin hari kian meningkat, namun tidak diimbangi dengan peningkatan pemahaman petani dalam menggunakan pestisida. Dampak dari pemakaian pestisida adalah pencemaran air,tanah,udara serta berdampak pada kesehatan petan.(MG Catur Yuantari.2013).

Pestisida di indonesia yang banyak digunakan adalah insektisida $55,42 \%$, herbisida $12,25 \%$, fungsida $12,05 \%$, repelen $3,61 \%$, zat pengatur pertumbuhan $3,21 \%$, nematisida $0,44 \%$, dan $0,40 \%$ adjuvant serta lain-lain berjumlah $1,41 \%$ dari gambaran ini menunjukkan bahwa insektisida merupakan jenis pestisida yang paling banyak digunakan, tingkat pemakaian pestisidanya cukup tinggi adalah di Kabupaten Brebes, Jawa Tengah. (Alimah Fauzan, 2017).

Berdasarkan teori Lawrence Green ( 1980 ) dalam maulan ( 2009 ) bahwa faktor-faktor yang mempengaruhi perilaku seseorang tentang kesehatan selain pengetahuan adalah sikap,pengetahuan dan pendidikan.Hal ini juga didukung oleh hasil wawancara, dimana mayoritas petani mengatakan bahwa tanpa menggunakan Alat Pelindung Diri (APD) petani tetap dalam kondisi sehat, sehingga petani menyikapi bahwa kontak dengan pestisida dianggap biasabiasa saja. ( Rario dkk, 2005 ). 
Jurnal Sulolipu : Media Komunikasi Sivitas Akademika dan Masyarakat

Vol. 20 No.12020

e-issn : 2622-6960, p-issn : 0854-624X

Kasus keracunan terjadi pada petani salah satunya disebabkan karena tidak menggunakan alat pelindung diri pada saat menggunakan pestisida. Sehingga petani berpotensi untuk terpapar dengan pestisida.Salah satu cara untuk mengurangi risiko terpapar yaitu dengan menggunakan alat pelindung diri. Alat pelindung diri adalah suatu alat yang mempunyai kemampuan untuk melindungi seseorang yang fungsinya mengisolasi sebagian atau seluruh tubuh dari potensi bahaya di tempat kerja. (Permenaktrans, 2010 ).

\section{Desain dan Variabel Penelitian}

\section{Desain Penelitian}

Jenis penelitian yang digunakan adalah observasional analitik dengan pendekatan Cross Sectional, yaitu variabel dependen dan variabel independen di ukur secara bersamaan.

Variabel Penelitian

1) Variabel bebas yaitu variabel yang mempengaruhi variabel terikat dalam hal ini yaitu sikap dan pengetahuan.

2) Variabel terikat adalah variabel yang dipengaruhi oleh variabel bebas dalam hal ini yaitu penggunaan APD.

3) Variabel pengganggu adalah variabel yang mempengaruhi variabel terikat dalam hal ini adalah pendidikan.

\section{Populasi dan Sampel \\ Populasi}

Yang menjadi populasi dari penelitian ini adalah seluruh petani padi yang ada $\mathrm{Di}$ Desa Pakkaba Kecamatan Galesong Utara Kabupaten Takalar yaitu 300 petani.

\section{Sampel}

Sampel adalah sebagian dari populasi petani padi yang ada di Desa Pakka'ba Kecamatan Galesong Utara Kabupaten
Takalar. Jumlahnya ditentukan dengan rumus ( slovin)..

\section{Pengumpulan Data \\ Data Primer}

Data primer adalah data yang langsung diperoleh pada petani padi $\mathrm{Di}$ Desa Pakka'ba Kecamatan Galesong Utara Kabupaten Takalar mengenai pengetahuan dan sikap penggunaan APD.

\section{Data Sekunder}

Data sekunder ini diperoleh dengan mengumpulkan data yang bersumber dari literatur-literatur, bahan kuliah, buku-buku dan hasil penelitian lainnya yang berhubungan dengan objek penelitian.

\section{Analisa Data}

Analisis Univariat Analisis ini dilakukan terhadapa setiap variabel dari hasil penelitian ini untuk melihat distribusi frekuensi dan persentase yaitu meliputi Observasi pengetahuan dan sikap para pada

HASIL

Tabel 1

Distribusi Frekuensi Berdasarkan Pengetahuan Petani Di Desa Pakkaba' Kec. Galesong Utara Kab. Takalar Tahun 2019

\begin{tabular}{llll}
\hline No & Pengetahuan & $\mathbf{N}$ & $\%$ \\
\hline 1 & Tinggi & 49 & $29 \%$ \\
2 & Rendah & 122 & $71 \%$ \\
\hline Total & 171 & $100 \%$ \\
Sumber: Data Primer & &
\end{tabular}

Tabel 2

Distribusi Frekuensi Berdasarkan Sikap Petani Di Desa Pakkaba' Kec. Galesong Utara Kab. Takalar Tahun 2019

\begin{tabular}{llll}
\hline No & Sikap & $\mathbf{n}$ & $\%$ \\
\hline 1 & Tinggi & 76 & $44 \%$ \\
2 & Rendah & 95 & $56 \%$ \\
\hline Total & & 171 & $100 \%$ \\
\hline
\end{tabular}

Sumber: Data Primer

Tabel 3 
Jurnal Sulolipu : Media Komunikasi Sivitas Akademika dan Masyarakat

Vol. 20 No.12020

e-issn : 2622-6960, p-issn : 0854-624X

Distribusi Frekuensi Berdasarkan Sikap

Petani Di Desa Pakkaba' Kec. Galesong Utara Kab. Takalar Tahun 2019

\begin{tabular}{llll}
\hline No & Sikap & $\mathbf{n}$ & $\%$ \\
\hline 1 & Tinggi & 76 & $44 \%$ \\
2 & Rendah & 95 & $56 \%$ \\
\hline Total & & 171 & $100 \%$ \\
\hline \multicolumn{2}{l}{ Sumber: Data }
\end{tabular}

Sumber: Data Primer

Tabel 4

Hubungan antara pengetahuan petani dengan penggunaan Alat Pelindung Diri (APD) Di Desa Pakkaba' Kec. Galesong Utara Kab. Takalar Tahun 2019.

\begin{tabular}{|c|c|c|c|c|c|c|c|}
\hline \multirow{3}{*}{$\begin{array}{l}\text { Penget } \\
\text { ahuan }\end{array}$} & \multicolumn{4}{|c|}{ Penggunaan APD } & \multicolumn{2}{|c|}{ Jumlah } & \multirow{3}{*}{$\begin{array}{c}P \\
\text { valu } \\
\mathrm{e}\end{array}$} \\
\hline & \multicolumn{2}{|c|}{ Rendah } & \multicolumn{2}{|c|}{ Tinggi } & & & \\
\hline & $\mathrm{N}$ & $\%$ & $\mathrm{n}$ & $\%$ & $\mathrm{~N}$ & $\%$ & \\
\hline & 2 & 60 & 2 & 40 & 4 & 10 & \multirow{8}{*}{$\begin{array}{c}0.0 \\
0\end{array}$} \\
\hline \multirow{2}{*}{ Tinggi } & 9 & $\%$ & 0 & $\%$ & 9 & $0 \%$ & \\
\hline & 1 & & & & 1 & & \\
\hline Renda & 2 & 10 & & 0 & 2 & 10 & \\
\hline \multirow[t]{3}{*}{ h } & 2 & $0 \%$ & 0 & $\%$ & 2 & $0 \%$ & \\
\hline & 1 & & & & 1 & & \\
\hline & 5 & 88 & 2 & 12 & 7 & 10 & \\
\hline Total & 1 & $\%$ & 0 & $\%$ & 1 & $0 \%$ & \\
\hline
\end{tabular}

Sumber: Data Primer

\section{PEMBAHASAN}

1. Hubungan antara pengetahuan Petani dengan penggunaan alat pelindung diri

Berdasarkan hasil penelitian menunjukkan bahwa ada hubungan yang signifikan antara pengetahuan dengan penggunaan alat pelindung diri (APD) pada petani di Desa Pakka'ba Kecamatan Galesong Utara Kabupaten Takalar. Hal ini didasarkan pada hasil uji Chi Square dari hasil analisis Continuity Correction yang diperoleh adala $p$ value 0,00 ( $p$ value $>0,05$ ). Hasil penelitian ini menjelaskan bahwa sebagian petani mempunyai tingkat pengetahuan tinggi yaitu sebanyak 49 orang(29\%) dan pengetahuan rendah sebanyak 122 orang $(71 \%)$. Petani yang memiliki pengetahuan tinggi sebanyak 49 orang $(29 \%)$ yang menggunakan APD tinggi sebanyak 20 orang(12\%), sedangkan petani yang menggunakan APD rendah sebanyak 29 orang(17\%). Petani yang mempunyai pengetahuan rendah sebanyak 29 orang(17\%) yang menggunakan APD tinggi sebanyak 0 orang $(0 \%)$, sedangkan petani yang menggunakan APD rendah sebanyak 122 orang $(71 \%)$.

Hasil penelitian ini menjelaskan bahwa petani yang memiliki pengetahuan rendah dan tinggi dalam penggunaan alat pelindung diri (APD) tidak menggunakan secara lengkap, dimana petani tidak menggunakan masker, tidak menggunakan sarung tangan, dan tidak menggunakan sepatu kerja. Dalam hal ini pengetahuan untuk penggunaan alat pelindung diri (APD) masih kurang. Hasil penelitian ini sejalan dengan penelitian Wismaninngsih 2015 tentang faktor yang berhubungan dengan penggunaan alat pelindung diri (APD) pada petani penyemprot di Kecamatan Ngantru Kabupaten Tulungagung dari hasil analisis Fisher's Exact Test menunjukkan bahwa pengetahuan mempunyai hubungan yang signifikan terhadap penggunaan APD dengan nilai p $0.001(p<0,05)$. Semakin tinggi pengetahuan petani terhadap pentingnya penggunaan APD maka semakin baik perilaku petani dalam penggunaan APD.

Hasil penelitian ini sejalan dengan penelitian Faris Khamdani (2009). Hasil penelitian Faris Khamdani (2009) tentang Hubungan antara Pengetahuan dan Sikap dengan pemakaian Alat Pelindung Diri Pestisida Semprot pada petani di Desa Angkatan Kidul Pati Tahun 2009 didapatkan hasil bahwa responden yang mempunyai pengetahuan kurang dan tidak memakai APD lengkap sebanyak 32 orang atau $94,1 \%$, sedangkan responden yang memiliki pengetahuan baik dan cukup yang tidak memakai APD lengkap sejumlah 13 orang atau $28,3 \%$. 
Responden dengan pengetahuan yang kurang dan memakai APD lengkap berjumlah 2 orang atau 5,9\% sedangkan responden yang mempunyai pengetahuan bak dan cukup yang memakai APD lengkap 33 orang atau $71,7 \%$.

Dalam penelitian ini petani berumur $>50$ tahun dengan masa kerja $>20$ tahun dan sebagian besar petani tamat sekolah menengah pertama (SMP) dan sebagian besar sekolah dasar (SD), beberapa diantaranya memiliki pendidikan sampai jenjang Sekolah Menengah Atas (SMA). Petani yang tidak tamat Sekolah Dasar (SD) dan Sekolah menengah pertama (SMP) sebagian besar memiliki tingkat pengetahuan rendah, sedangkan petani yang memiliki pendidikan sampai dengan Sekolah Menengah Atas (SMA) memiliki pengetahuan yang tinggi . Hal ini menunjukkan bahwa pendidikan formal meberikan pengaruh besar dalam membuka wawasan dan pemahaman terhadap nilai baru yang ada dilingkungannya

Alasan responden tidak menggunakan alat pelindung diri (APD) yang lengkap karena masih kurangnya pemahaman responden tentang syarat-syarat alat pelindung diri dan manfaat alat pelindung diri. Sebagian besar petani tidak menggunakan alat pelindung diri karena merasa terganggu atau tidak nyaman terutama penggunaan sarung tangan, masker, dan sepatu boot. Beberapa responden beranggapan bahwa mereka tidak merasakan dampak yang ditimbulkan dari tidak menggunakan alat pelindung diri dan beberapa responden juga beranggapan bahwa meskipun mereka menggunakan alat pelindung diri yang lengkap mereka tetap merasakan dampak yang ditimbulkan seperti saat penyemprotan mereka merasa pusing. Dampak tersebut timbul ketika petani menyemprot dengan cara yang salah pada saat penyemprotan pestisida, seperti petani yang menyemprot berlawanan arah dengan arah angina dan melakukan penyemprotan pada siang hari. Menurut WHO 1998, Paparan yang berlangsung terus-menerus lebih berbahaya dari pada paparan yang terputus-putus pada waktu yang sama. Jadi pemaparan yang telah lewat perlu diperhatikan bila terjadi resiko pemaparan baru. Karena itu penyemprot yang terpapar berulang kali dan berlangsung lama dapat menimbulkan keracunan.

Untuk membentuk perilaku sehat masyarakat perlu diberikan pengetahuan atau informasi-informasi yang benar dan lengkap tentang penyakit-penyakit dan pelayanan kesehatan. Kepercayaan yang tidak didasarkan pada pengetahuan yang benar dan lengkap, akan menyebabkan kesalahan bertindak. Perilaku yang didasarkan oleh pengetahuan akan lebih langgeng dari pada perilaku yang tidak didasari oleh pengetahuan. ( Soekidjo Notoatmodjo, 2014 Dalam Mithaul Jannah Ismail).

\section{Hubungan Sikap Petani dengan penggunaan alat pelindung diri di Desa Pakka'ba}

Berdasarkan hasil penelitian menunjukkan bahwa ada hubungan yang signifikan antara sikap petani dengan penggunaan alat pelindung diri (APD) di Desa Pakka'ba Kecamatan Galesong Utara Kabupaten Takalar. Hal ini didasarkan pada hasil uji Chi Square dari hasil analisis Continuity Correction diperoleh adalah $p$ value 0,00 ( $p$ value >0,05). Hasil penelitian ini menjelaskan bahwa petani mempunyai sikap tinggi sebanyak 76 orang(44\%) dan sikap rendah sebanyak 95 orang(56\%). Petani yang memiliki sikap tinggi terhadap 
penggunaan APD 76 orang(44\%) yang menggunakan APD tinggi sebanyak 19 orang(11\%), sedangkan yang mempunyai APD rendah sebanyak 57 orang(33\%). Petani yang memiliki sikap rendah terhadap penggunaan APD sebanyak 95 orang $(56 \%)$ yang menggunakan APD tinggi sebanyak 1 orang( $1 \%$ ) dan yang menggunakan APD rendah sebanyak 94 orang(55\%).

Hasil penelitian ini menjelaskan bahwa petani memiliki sikap tinggi (baik) terhadap penggunan alat pelindung diri (APD), mereka tetapi tidak menggunakan alat pelindung diri (APD) secara lengkap dalam artian tindakan untuk menggunakan alat pelindung diri masih kurang. Sehingga dapat dilihat bahwa sikap tidak selalu mencerminkan tindakan seseorang atau tindakan seseorang seringkali bertentangan dengan sikapnya.

Hasil penelitian ini sejalan dengan peneltian Wismaningsih 2015 tentang faktor yang berhubungan dengan penggunaan alat pelindung diri (APD) pada petani penyemprot di Kecamatan Ngantru Kabupaten Tulung Agung dari hasil analisis Fisher's Exact Test menunjukkan bahwa sikap mempunyai hubungan yang signifikan terhadap penggunaan APD dengan nilai $p 0,000$. Sikap seseorang berkaitan dengan persepsi, kepribadian, dan motivasi yang timbul sebagai reaksi dari pengalaman atau pengetahuan yang dimilikinya. Pengetahuan tentang APD yang baik disertai dengan reaksi yang positif menimbulkan kesadaran dan motivasi dari petani untuk melindungi dirinya dari bahaya pestisida dengan cara meggunakan APD.

Sikap merupakan suatu kecenderungan untuk mengadakan tindakan terhadap suatu objek, dengan suatu cara yang menyatakan adanya tanda-tanda untuk menyenangi atau tidak menyenangi objek tersebut. Sikap hanyalah sebagian dari perilaku manusia. Sikap adalah reaksi atau respon yang masih tertutup dari seseorang terhadap stimulasi atau objek. Sikap secara nyata menunjukkan konotasi adanya kesesuaian reaksi terhadap stimulasi tertentu yang dalam kehidupan sehari-hari merupakan reaksi yang bersifat emosional terhadap stimulus social. (Notoatmodjo, 2003 dalam Khamdani 2009).

Dalam penelitian ini menunjukkan bahwa sikap petani terhadap penggunaan APD kurang baik (rendah), meskipun sikap petani kurang baik ada beberapa faktor yang mempengaruhi penggunaan APD, seperti kenyamanan dalam bekerja. Sebagian besar petani tidak menggunakan alat pelindung diri yaitu sebanyak 151 responden atau 88\%, selain itu faktor cuaca juga mempengaruhi para petani padi.

Ketersediaan alat pelindung diri yang lengkap sangat dibutuhkan untuk mewujudkan sikap petani dalam bentuk tindakan. Sikap petani yang baik belum tentu terwujud tanpa adanya sarana atau prasarana pendukung dalam pengaplikasian pestisida. Oleh karena itu, sangat perlu adanya penyuluhan tentang jenis-jenis alat pelindung diri yang wajib digunakan petani pada saat pengaplikasian pestisida, sehingga petani dapat menyediakan alat pelindung diri tersebut.

Pada penelitian ini sebagian besar petani memiliki masa kerja $>10$ tahun dan beberapa petani memiliki masa kerja $>10$ tahun. Petani dengan masa kerja >10 tahun memiliki sikap yang rendah (tidak baik) terhadap penggunaan alat pelindung diri begitu juga dengan petani yang memiliki masa kerja $>10$ tahun juga memiliki sikap yang rendah (tidak baik) dalam artian tidak menggunakan alat pelindung diri yang lengkap. Hal ini menunjukkan bahwa walaupun petani 
Jurnal Sulolipu : Media Komunikasi Sivitas Akademika dan Masyarakat

Vol. 20 No.12020

e-issn : 2622-6960, p-issn : 0854-624X

yang memiliki masa kerja yang lama sekalipun, yang memiliki pengalaman dalam melakukan pekerjaannya belum mampu menerapkan penggunaan APD yang lengkap dalam melindungi dirinya ketika melakukan kegiatan penyemprotan.

\section{KESIMPULAN}

Berdasarkan hasil penelitian ini, dapat disimpulkan bahwa ada hubungan antara pengetahuan dengan penggunaan alat pelindung diri di Desa Pakka'ba Kecamatan Galesong Utara Kabupaten Takalar, dimana $p$ value $=0,00$ ( $p$ value $>0,05$ ) dan berdasarkan hasil penelitian ini, dapat disimpulkan bahwa ada hubungan antara sikap dengan penggunaan alat pelindung diri di Desa Pakka'ba Kecamatan Galesong Utara Kabupaten Takalar, dimana $p$ SARAN value $=0,00(p$ value $>0,05)$.

$\quad$ Petani diharapkan lebih
meningkatkan pemahaman dan
kesadaran akan pentingnya
penggunaan alat pelindung diri (APD)

secara lengkap dengan mengikuti kegiatan-kegiatan penyuluhan maupun pelatihan untuk meningkatkan keselamatan dan kesehatan kerja petani. Selain itu, untuk meningkatkan kenyamanan petani dalam menggunakan alat pelindung diri dapat dilakukan dengan cara megikuti simulasi tentang cara penggunaan alat pelindung diri yang baik dan benar, sehingga dengan adanya penggunaan APD yang baik dan benar dapat meningkatkan kenyamanan dak keselamatan para petani.

Pemerintah diharapkan dapat meningkatkan program promosi Kesehatan dan Keselamatan Kerja dengan melakukan pembinaan bagi petani padi lewat kerjasama dengan Puskesmas setempat dan rutin melakukan koordinasi dengan petanin melalui pertemuan-pertemuan antar petani serta memberikan reward kepada petani dalam rangka membentuk sikap positif petani dalam penggunaan alat pelindung diri (APD).

\section{DAFTAR PUSTAKA}

2012. Hubungan antara tingkat pengetahuan tentang bahaya pestisida dengan kebiasaan petani menggunakan alat pelindung diri ( APD ) ketika menyemprot padi di desa laban kecamatan mojo laban. Karya Tulis ilmiah .Jurusan Ilmu Kesehatan Universitas Muhammadiyah Surakarta.

Eva F. Gudgin Dickson.2012.Personal Protective Equipment for Chemical, Biological, and Radiological Hazards :Design, Evaluation, and Selection. Canada :Jhon Wiley \& Sons, inc

Faris Khmdani, 2009. Hubungan Antara Pengetahuan Dan Sikap Dengan Alat Pelindung Diri Dari Pestisida Semprot Pada Petani Di Desa Angkatan Kidul Pati.

Fauzan,Alimah.2017.Perempuan Paling Rentan Terpapar Racun Pestisida.(online) https://infest.or.id > Berita > CatatanPengetahuan, diaksespada 23 November 2017.

Frity. 2017. Faktor-faktor Keterpaparan Pestisida Pada Petani Tanaman Hortikultura Di Perkebunan Wawo Kota Tomohon 2017.( online ) https://ejournalhealth.com/index.php/kesmas 
Jurnal Sulolipu : Media Komunikasi Sivitas Akademika dan Masyarakat

Vol. 20 No.12020

e-issn : 2622-6960, p-issn : 0854-624X

Faijin,Akbar. 2018. Hubungan antara pengetahuan dan sikap dengan pemakaian APD ( AlatPelindungDiri ) pada petani bawang merah. Skripsi jurusan kesehatan masyarakat fakultas kesehatan universitas muhammadiyah Surakarta. Surakarta

HeidyManggopaDkk. 2016. Hubungan antara pengetahuan dan sikap terhadap penggunaan alat pelindung diri pada petani pengguna pestisida di desakembang sari kecamatan dumoga timur kabupaten bolaang mongondow Provinsi Sulawesi Utara.

Menteri Tenaga Kerja Dan Transmigrasi Republik Indonesia.2010. Peraturan Menteri Tenaga Kerja Dan Transmigrasi Republik Indonesia Nomor Per.08/Men/Vii/2010 Tentang Alat Pelindung Diri. (online)https://betterwork.org/in-labourguide, diaksespada 23 November 2017.

MG CaturYuantari. 2013. Tingkat pengetahuan petani dalam menggunakan pestisida, tahun 2013

Nurmin.2018. Perilaku Petani Penyemprotan Pestisida Terhadap Penggunaan Alat Pelindung Diri di Desa Tonrong Rijang Kecamatan Baranti Kabupaten Sidenreng Rappang.Karya Tulis ilmiah.Jurusan Kesehatan Lingkungan Politeknik Kesehatan Makassar.

Rahmawati, YevianaDwi. 2014. Pengaruh Faktor Karakteristik Petani dan Metode Penyemprotan terhadap Kadar Kolinesterase. (online)journal.unair.ac.id, diaksespada 23 November 2017.

Rifai, Usman. 2017. Faktor - Faktor Yang Berhubungan Dengan Kepatuhan Penggunaan Alat Pelindung Diri Pada Petani Padi Di Dukuh Sodong Kelurahan Purwosari Kecamatan Mijen Kota Semarang tahun 2017. (online)eprints.dinus.ac.id/22506, diaksespada 23 November 2017.

Rario, B, Kastro, dan Su Ritohardoyo.2005. Persepsi dan Perilaku Petani dalam Penanganan Resiko Pestisida pada Lingkungan di Kelurahan Kelampungan Kecamatan Sabangau Kota Palangka Raya.Jurnal Manusia dan Lingkungan.Pusat studi Lingkungan Hidup universitas Gajah Mada.

Shobib, Muhammad Nur, dkk. 2013. Hubungan Antara Pengetahuan dan Sikap dengan Praktik Pemakaian (APD) Alat Pelindung diri Pada Petani Pengguna Pestisida di Desa Curut Kec Penawangan Kab GroboganTahun 2013. (online)Eprints.dinus.ac.id,diaksespada 23 November 2017.

Soekidjo Notoatmodjo .2014. Ilmu Perilaku dan Kesehatan Kerja. Yogyakarta: Deepublish

Wismaningsih, Endah Retnani dan Diantilas Oktaviasari. 2015. Faktor yang Berhubungan dengan Penggunaan Alat Pelindung Diri (APD) pada Petani Penyemprot di Kecamatan Ngantru KabupatenTulung agung. (online)https://ojs.iik.ac.id, diaksespada 23 November 2017. 